\title{
Uncertainties in Projected Rainfall over Brazil: The Role of Climate Model, Bias Correction and Emission Scenario
}

\author{
Carolina Natel de Moura ${ }^{\mathrm{a}, \mathrm{b}}$, Jan Seibert ${ }^{\mathrm{b}}$; Miriam Rita Moro Mine ${ }^{\mathrm{a}}$ \\ ${ }^{\text {a}}$ Federal University of Parana, Hydraulics and Sanitation Department

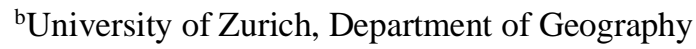 \\ *Corresponding author \\ carolina.natel@gmail.com
}

\begin{abstract}
Study region

Twenty-six rainfall gauge stations distributed over Brazil

\section{Study focus}

The aim of this study is to answer four main questions: How well the Eta regional climate model simulates past precipitation over Brazil? What is the impact of bias correction on the reduction of model's biases? What is the contribution of climate models, bias correction and emission scenarios to the total uncertainty of projected precipitation? And finally, what is the projected change in precipitation over Brazil?
\end{abstract}

\section{New hydrological insights for the region}

The performance of raw simulations of the Eta regional climate models vary spatially over Brazil, being the Amazon and North region the regions with the highest biases. However, while the model fails in accuracy, it represents well the annual cycle of the precipitation and the signal of the future changes is robust (that is, it agrees with the signal of the changes after the bias correction and the models agree with each other). The bias correction presented a great impact in the bias reduction. Greater uncertainty levels are attributed to the bias correction followed by the climate models and interaction between climate model and bias correction. The emission scenario is the less contributor to the total uncertainty. Projected precipitation changes indicated a decrease in the daily precipitation and extreme precipitation in the Amazon and North Brazil and increase in the daily precipitation in Southern. The precipitation in winter is expected to increase. Under the IPCC scenario RCP 8.5, homogeneoulsly drier conditions are projected for the entire country.

Keywords: climate change assessment, uncertainty analysis, robustness, RCP4.5, RCP8.5

\section{Introduction}

Climate change directly affects precipitation patterns, such as quantity, intensity, frequency and type (Trenberth, 2011). Consequently, it is likely that we will see changes in the hydrological cycle. Reductions or increases in the amounts of precipitation can affect food production, power generation and water supply. On the other hand, changes in the intensity, frequency and type of precipitation are likely to increase the risk of hydrological extremes, such as floods and droughts. To avoid the worst impacts of climate change, we need to understand the 
spatial variability and magnitude of changes in rainfall, improving decision-making and increasing the adaptability of vulnerable communities.

Regarding Brazil, in the last four decades, it has occurred an increase in rainfall in the south and southeast (Zilli et al., 2017, Ávila et al. 2016; Zandonadi et al. 2016; Sá et al. 2018), while the northeast of the country has shown a reduction of precipitation (Carvalho et al., 2020, Costa et al., 2020). On the other hand, no consistent changes are observed for the Amazon region, where the rainy and drought periods seem to be more associated with the natural variability (Marengo et al., 2004). In the future, the precipitation changes vary geographically, projections over the region indicate a reduction in precipitation of $22 \%$ in Northeast Brazil, and increase of $25 \%$ in Southeastern South America (Magrin et al., 2014).

However, although many studies have examined the relationships between precipitation patterns and climate change, and the models relatively agree in the signal of the changes, the future magnitude of the changes are still unclear because of the large uncertainty in General Circulation Model (GCM) simulations of precipitation (Woldemeskel et al., 2012). The GCMs are the main tool to simulate future changes in precipitation due to for example external forcings as the increase of the greenhouse gases in the atmosphere.

Due to the coarse resolution of GCMs, a traditional approach is the downscaling, which is the transfer of the large-scale information from GCMs to a regional or local scale, resulting in a Regional Climate Model (RCM). However, even after the downscaling, biases are likely to remain in the projections, making it necessary a bias correction technique (Addor and Seibert, 2014). Besides that, the climate models are forced by a set of boundary conditions determined by emission scenarios, which also aggregate uncertainties to the projected precipitation. For a better understanding of all the elements of this cascade chain in its specific uncertainties, see Hakala et al. (2019).

These uncertainties may lead to unrealistic projections of the changes in precipitation and consequently, non-robust climate change impact projections. There is a consensus in the literature about the relative importance of these different sources of uncertainty, being the climate model the dominant source in hydrological impact assessments (Wilby and Harris, 2006; Prudhomme and Davies, 2009; Kay et al., 2009; Arnell, 2011). However, the importance of these sources may vary temporarily, according to the scale (Shrestha et al., 2016) and variable (e.g. mean, low or high extremes) (Meresa and Romanowicz, 2017).

The state of art for the assessment of the climate change impacts include the evaluation without any quantification of uncertainty (Gosain; Rao and Basuray, 2006; Thodsen, 2007), focus only on climate uncertainty and neglect the others (Woldemeskel et al., 2014) or even take a single climatic projection and only assess the impact model uncertainty (Steele-Dunne et al., 2008). The impact model uncertainty in general is evaluated as the minor contributor to the total uncertainty given the large uncertainty of climate models and boundary conditions (Hattermann et al., 2018, Zorndt and Schlurmann, 2019). Certain approaches such as multi-model ensembles are strongly recommended to reduce the uncertainties of the climate change impact, as well as statistical post processing (bias correction) of the model outputs can reduce the uncertainty level (Kundzewicz et al., 2018), but the latter is still controversial in the literature (Ehret et al., 2012). Some authors argue that the need of the bias correction should be questioned, once the method 
may affect the consistency between the climate model output variables, as temperature and precipitation for example (Muerth et al., 2013). Another issue is that bias correction assumes that the bias present in the past series will remain in the future, which is very unlikely and more, the bias correction may even affect the climate change signal for the future (Ehret et al., 2012).

Especially in Brazil, recent studies showed that the climate change assessments conducted in the country lack in addressing the uncertainties ineherent to the modeling process, being the use of several GCMs and/or RCMs not a common practice, as well as the evaluation of the bias correction methods applied and the use of multi-model ensembles (Amorim and Chaffe, 2019a, Amorim and Chaffe, 2019b). On the other hand, the bias correction, it is either not applied at all or unscrupulously applied without testing the need in climate change assessments. The country also lacks a broad validation analysis of the last version of the Eta regional climate model available by the INPE (National Institute of Space Research) in terms of raw biases of the simulations and the impact of bias correction in the reduction of the errors. Moreover, we are not aware of Brazilian studies analysing the contribution of each source of uncertainty in the total ucertainty, which would provide information for the modelers, and consequently, best results for the climate change communication and decision-making.

This study aims to answer four main questions: How well the Eta regional climate model simulates past precipitation over Brazil/Are there regions where the biases are particularly large? What is the impact of bias correction on the reduction of model's biases and/or is bias correction necessary? What is the contribution of climate models, bias correction and emission scenarios to the total uncertainty of projected precipitation? And finally, what is the projected change in precipitation over Brazil?

We argue that understanding the limitations/strengths of the projected simulations, as well as the impact of each element of the modeling chain (climate model, bias correction, emission scenario) in the final model is essential to highlight the importance of the uncertainty addressing in climate change studies and guiding the modelers in the future.

\section{Study area and data}

Brazil covers a large area $\left(8,515,767.049 \mathrm{~km}^{2}\right)$ and has a high rainfall spatial variability, mainly linked to a particular mode of the large-scale variation called the Southern Oscillation (SO). In the northwest, the Amazon basin is characterised by large amounts of rainfall. Together with the Southern Brazil, these regions are the wettest in the country, being the Southern characterised by high spatially variable rainfall. In Northeast Brazil, the rainfall amount is low with an extensive semiarid area in the interior (Rao and Hada, 1990). Summer is the most common season of high precipitation days in the majority of Brazil, with two main exceptions, part of the coast of Northern Brazil (fall) and Southern Brazil (spring) (Chagas et al., 2020).

To study the uncertainties in the projected precipitation over Brazil, we used both groundlevel precipitation gauges and projected by Regional Climate Model data. The gauge precipitation data were obtained from the National Institute of Meteorology (INMET; http://www.inmet.gov.br/portal/). From the 'conventional' stations (i.e. not automated) available by the INMET (238 in total), we first selected those with data between the period 1961 to 2005. Then, we filtered the gauge stations with less than about $10 \%$ of missing data (i.e. less than 2000 
missing values), totalizing 26 gauge stations across the country (Figure 1). The main characteristics of the rainfall gauge stations, including gauge id, name, location, altitude and long - term annual precipitation are presented in Table S1 in the Supplementary Material. Missing values were excluded from the analysis, and because of that, each station has a different dataset length, but with at least $90 \%$ of data in the period).

The climate projections were obtained from an upgraded version of the Eta Regional Climate Model (RCM) (Mesinger et al., 2012), generated by the INPE (National Institute of Space Research). This version of the Eta model was configured in the resolution of $20 \mathrm{~km}$, covering South America, Central America, and Caribbean (Chou et al., 2014). The dynamical downscaling was run using the Eta model on four different Global Climate Models (GCMs), being them the HadGEM2-ES (Collins et al., 2011), MIROC5 (Watanabe et al., 2011), CanESM2 (Chylek et al., 2011) and BESM (Nobre et al., 2013), described in Table 1.

The projections were available in two periods: Historical (1961 - 2005) and Representation Concentration Pathway (RCP) (2006 - 2099). From 2006 the simulations run using the IPCC emission scenarios RCP 4.5 and RCP 8.5 (Chou et al., 2014). The RCP 4.5 refers to a scenario reaching about $650 \mathrm{ppm}$ of $\mathrm{CO} 2$ equivalent at the end of the century while in the RCP8.5, the equivalent CO2 exceeds 1000 ppm. Other RCP scenarios are described by Moss et al (2010).

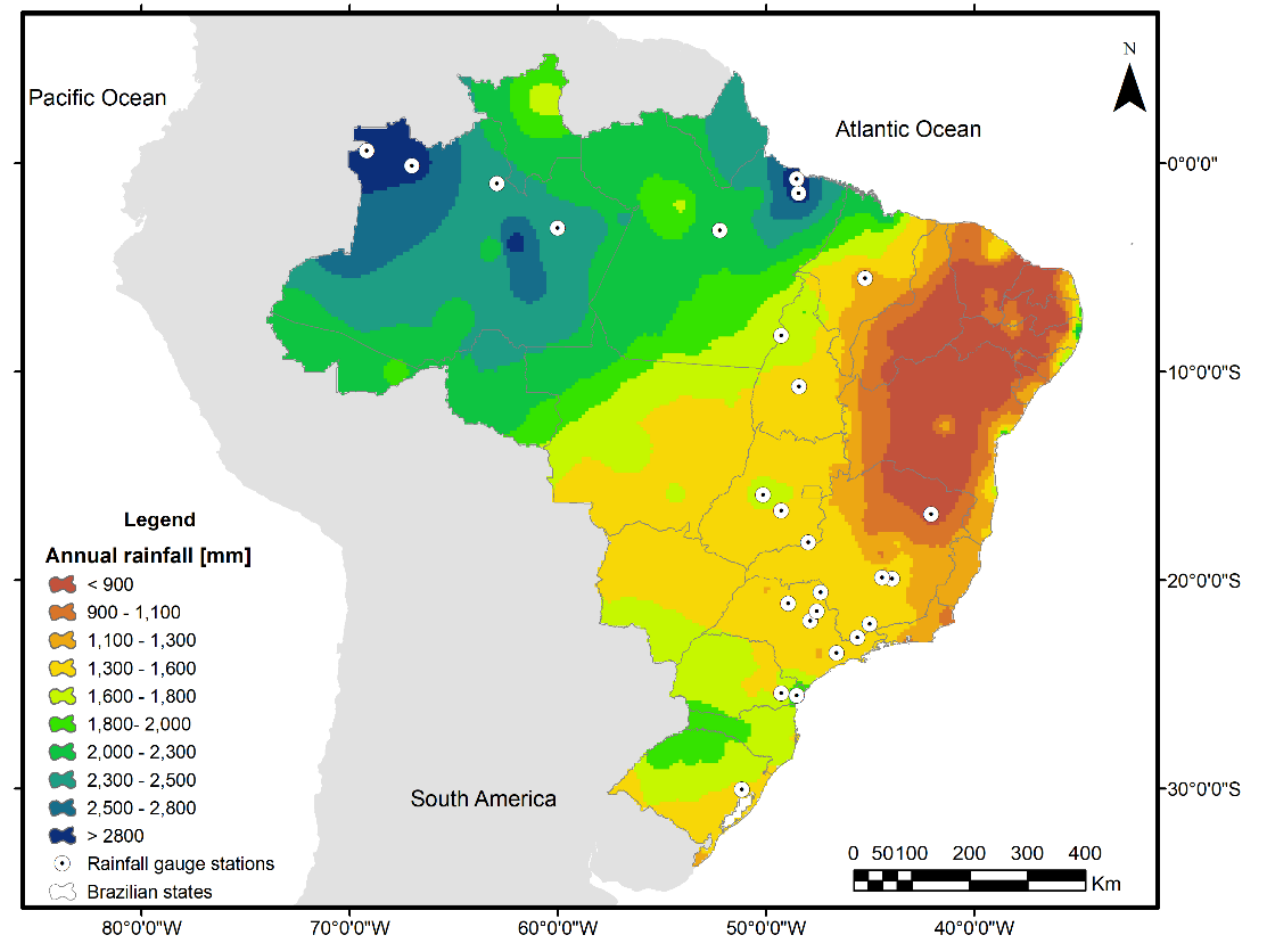

Figure 1 - Location of the precipitation gauge stations in Brazil. 
Table 1. Global climate model description.

\begin{tabular}{|c|c|c|}
\hline GCM & Full name of GCM & Institution \\
\hline HadGEM2-ES & $\begin{array}{l}\text { Hadley Centre Global } \\
\text { Environmental Model } \\
\text { version } 2 \text { - Earth System }\end{array}$ & Hadley Centre \\
\hline MIROC5 & $\begin{array}{l}\text { Model for Interdisciplinary } \\
\text { Research on Climate } \\
\text { version } 5\end{array}$ & $\begin{array}{l}\text { Atmosphere and Ocean Research Institute, } \\
\text { University of Tokyo, National Institute for } \\
\text { Environmental Studies and Japan Agency for } \\
\text { Marine-Earth Science and Technology. }\end{array}$ \\
\hline CanESM2 & $\begin{array}{l}\text { Canadian Earth System } \\
\text { Model version } 2\end{array}$ & $\begin{array}{l}\text { Canadian Centre for Climate Modelling and } \\
\text { Analysis (CCCMA) }\end{array}$ \\
\hline $\begin{array}{l}\text { BESM - OA } \\
2.5 .1\end{array}$ & $\begin{array}{l}\text { Brazilian Earth System } \\
\text { Model }\end{array}$ & National Institute of Space Research (INPE) \\
\hline
\end{tabular}

The Eta regional climate model simulations were obtained at <https://projeta.cptec.inpe.br>. Data downloaded on May 1, 2020.

\section{Methods}

\subsection{Bias correction}

We applied the Linear Scaling (Lenderink, Buishand and Deursen, 2007) and the Empirical Quantile Mapping (Amengual et al., 2012) under two correction versions. First, we calculated the correction factors on a yearly basis (a single factor for the entire series), and after on a monthly basis (one factor per month). It was used measured at gauge stations and simulated data in a past period at the same location for the estimation of the correction factors.

First, we split the historical period $(1961$ - 2005) data into training $(80 \%)$ and the test period $(20 \%)$. The training period refers to that used for the estimation of the correction factors and the test period for the evaluation of the bias correction methods' performance. The split was made chronological (i.e. without random shuffle), in this way, we also evaluated the ability of the method to be applied in different climate conditions, especially if there is a non-stationarity in the historical period. Once estimated the correction factors based on the differences between the observed and simulated data in the training period, the correction factors were applied both in the test period (for the bias'correction evaluation) as well as in the future series.

\subsubsection{Linear Scaling}

The Linear Scaling is a simple method to correct variables based on long-term mean observed (Lenderink, Buishand and Deursen, 2007). Precipitation is corrected by the multiplication of the simulated value by a factor based on the ratio of long-term mean observed and simulated by the model (Equation 1).

$$
P_{\text {sim }}^{\text {corr }}(\mathrm{t})=P_{\text {sim }}(t) \cdot\left[\frac{\mu\left(P_{\text {obs }}^{\text {historical }}(t)\right)}{\mu\left(P_{\text {sim }}^{\text {historical }}(t)\right)}\right]
$$


Where $P_{\text {sim }}^{\text {corr }}(\mathrm{t})$ is the simulated precipitation $[\mathrm{mm}]$ corrected for time $t, P_{\text {sim }}(t)$ is the simulated precipitation for time $t[\mathrm{~mm}], \mu\left(P_{o b s}^{\text {historical }}(t)\right)$ is the observed long-term mean precipitation in the historical period [mm] and $\mu\left(P_{\text {sim }}^{\text {historical }}(t)\right)$ is the simulated long-term mean precipitation in the historical period $[\mathrm{mm}]$.

\subsubsection{Empirical Quantile Mapping}

The Empirical Quantile Mapping (EQM) corrects the simulated Cumulative Distribution Function (CDF) by adding to the observed quantiles both the mean delta change and the individual delta changes in the corresponding quantiles (Amengual et al., 2012).

The method consists of calculating the changes, quantile by quantile, in the CDFs of daily climate model outputs between historical and successive future periods (time-slices with the same length of historical). These changes are rescaled based on the observed CDF for the same historical period and then added, quantile by quantile, to these observations to obtain new calibrated future CDFs that convey the climate change signal (Equation 2).

$$
p_{i}^{\text {corr }}=o_{i}+\bar{\Delta}+\Delta_{i}^{\prime}
$$

Where $p_{i}$ is the $\mathrm{i}^{\text {th }}$ ranked value of the simulated precipitation corrected, $o_{i}$ is the $\mathrm{it}^{\mathrm{h}}$ ranked value of the observed precipitation in historical period, $\bar{\Delta}$ is the mean delta change and $\Delta^{\prime}{ }_{i}$ is the individual delta change. The delta change, the mean delta change, and the individual delta change are obtained by Equations 3, 4 and 5, respectively.

$$
\begin{gathered}
\Delta_{i}=s_{f i}-s_{c i} \\
\bar{\Delta}=\frac{\sum_{i=1}^{n}\left(s_{f i}-s_{c i}\right)}{n}=\bar{s}_{f}-\bar{s}_{c} \\
\Delta^{\prime}{ }_{i}=\Delta_{i}-\bar{\Delta}
\end{gathered}
$$

Where $s_{f i}$ is the simulated precipitation for the future $[\mathrm{mm}], s_{c i}$ is the simulated precipitation for the historical period $[\mathrm{mm}], \Delta_{i}$ is the $\mathrm{i}^{\text {th }}$ ranked delta change $[\mathrm{mm}]$ and $n$ is the number of observations

The 'drizzle effect', which is the common overestimation of wet days by the RCMs (Maraun et al., 2010) was corrected based on a wet-threshold of $1.5 \mathrm{~mm}^{-d a y^{-1}}$, i.e. the minimum amount of precipitation considered as real precipitation, otherwise, we considered precipitation equals zero. This value was selected based on a general preliminary analysis of the EQM results.

\subsubsection{Statistical evaluation of the model biases}

Biases in climate model simulations are commonly detected by the comparison with observations. Jung (2005) pointed the mean as one of the simplest and most widely used diagnostics to detect climate model biases. Here, the performance of the uncorrected models' simulation and bias correction were evaluated through the Absolute value of the Mean Error 
$\left(A_{m e}\right)$ and the Absolute value of the Relative Mean Error $\left(A_{r m e}\right)$, given by Equation 6 and Equation 7, respectively.

$$
\begin{gathered}
A_{m e}=\left|\mu_{s i m}-\mu_{o b s}\right| \\
A_{r m e}=\frac{\left|\mu_{s i m}-\mu_{o b s}\right|}{\mu_{o b s}} .100
\end{gathered}
$$

Where, $A_{m e}$ is the estimated mean systematic error over the time period, and $A_{r m e}$ is the estimated relative mean error over the time period, $\mu_{\text {sim }}$ is the mean of the simulated precipitation, and $\mu_{o b s}$ is the mean of the observed precipitation. It's important to point that even if we estimate a $A_{m e}$ of zero (i.e., detecting no systematic error), this may be due to error cancelation while calculating the average and even so simulations and observations might be characterized by different variability or distributions (Teutschbein and Seibert, 2013).

\subsection{The climate change signal}

We analyzed the future changes of precipitation in two periods, the near future (2041 2070) and far future $(2070$ - 2099). The climatological reference normal or baseline (1961 1990) was used for computing the changes in the amount of precipitation. This period was chosen because it is a benchmark for climate change assessments (WMO, 2017). The climate change signal or the changes in future precipitation were estimated by the absolute change in millimeters (Equation 8) and the relative change in percentage (Equation 9).

$$
\begin{gathered}
y_{a b s}=\mu\left(P_{\text {sim }}^{\text {fut,sce }}(t)\right)-\mu\left(P_{\text {obs }}^{\text {baseline }}(t)\right) \\
y_{\text {rel }}=\frac{\mu\left(P_{\text {sim }}^{f u t, s c e}(t)-\mu\left(P_{\text {obs }}^{\text {baseline }}(t)\right)\right)}{\mu\left(P_{\text {obs }}^{\text {base }}(t)\right)} .100
\end{gathered}
$$

Where $y_{a b s}$ is the absolute precipitation change for the future (e.g.: near or far) $[\mathrm{mm}]$, $y_{\text {rel }}$ is the relative precipitation change for the future (e.g.: near or far) [\%], $\mu\left(P_{\text {sim }}^{f u t \text {,scenario }}(t)\right)$ is the average long-term projected precipitation in a certain future under a chosen scenario [mm] and $\mu\left(P_{o b s}^{\text {reference }}(t)\right)$ is the average long-term observed precipitation in the reference period (1961 - 1990) [mm].

The multi-model ensemble is a well-know approach in climate change assessments in order to address the uncertainties related to models, based on the assertion that no model performs better than another (Amorim and Chaffe, 2019a). In this study, we chose the ensemble median to estimate the changes in the precipitation, once the median is better suited to describe the average outcome of the ensemble simulations than the mean since outliers do not influence this value.

The robustness of the changes was assessed by the degree of agreement method (Solomon et al., 2007) and signal-to-noise ratio $\left(S_{\mathrm{NR}}\right)$ (Addor et al., 2014). For the agreement method, it was 
considered that the direction of a change is 'likely' when $66 \%$ or more of all individual model simulations agree in the direction (Mastrandrea et al., 2010). The signal-to-noise ratio was used to measure the significance of the changes when compared with the natural variability of the precipitation.

We adapted the method applied by Addor et al. (2014) for calculating the $S_{\mathrm{NR}}$. The noise $(N)$ or natural variability was estimated by the bootstrapping of the observed precipitation series in the baseline period (1961 - 1990) in 100 subsamples of the same length (30 years) with replacement. Afterwards, we randomly selected 500 pairs from the time series and we estimated the changes between these pairs. The standard deviation among these 500 relative changes was then used as an estimate of $N$, considered as the typical change between two time series in absence of climate change, i.e., as a result of climate natural variability over decadal time scales. The $\mathrm{S}_{\mathrm{NR}}$ was computed then by the ratio between the precipitation change $(y)$ and the noise $N$, in which a $S_{N R}$ higher than 1 means robust changes for the future, i.e. the signal is identified as significant change and emerges of the natural variability.

\subsection{Uncertainty analysis}

The variance of the change in precipitation was used as an estimate of the uncertainty. We used the ANOVA (Analysis of Variance) to quantify the contribution of the different sources of uncertainty to the final uncertainty. For each one of the chain combinations and each future period, we estimated the climate change signal (see Equation 8). The climate change signal was submitted to a log transformation to meet the assumptions of the parametric ANOVA test.

The contribution of the different sources of uncertainty to the total uncertainty was quantified by the following model adapted from Addor et al. (2014) (Equation 10).

$$
y_{i j k}=\mu+C_{i}+B_{j}+E_{k}+I_{i j k}+\varepsilon_{i j k}
$$

The climate change signal $\left(y_{i j k}\right)$ was divided into the mean change $\mu$ modulated by the main effects of three factors, the climate model $\left(C_{i}, i=\right.$ Eta-HadGEM2-ES, Eta-MIROC5, EtaCanESM2 and Eta-BESM), the bias correction method $\left(B_{j}, j=\right.$ Linear Scaling (yearly correction factor), Linear Scaling (monthly correction factor), Empirical Quantile Mapping (yearly correction factor) and Empirical Quantile Mapping (monthly correction factor), and the emission scenario $\left(E_{k}, k=\mathrm{RCP} 4.5\right.$ and RCP 8.5$)$, as well as the sum of the significant interactions between these factors $\left(I_{i j k}\right)$ and the residual error $\left(\varepsilon_{i j k}\right)$.

Interaction effects represent the combined effects of factors on the dependent measure. When an interaction effect is present, the impact of one factor depends on the level of the other factor. Part of the power of ANOVA is the ability to estimate and test interaction effects. As higher-order interactions are hard to physically justify (Addor et al., 2014), we assumed only first-order interactions, i.e., interactions between two factors.

The significance of the interactions was assessed by the F-test. If the interaction was not significant, the interaction was not included in the ANOVA model. The sum of squares of each element (main effects, interactions, and error term) was divided by the total sum of squares to 
compute the fraction of variance explained by this element (Von Storch and Zwiers, 2009, Bosshard et al., 2013).

\subsection{Experimental design}

We combined four RCM - GCM, four bias-corrected simulations and two emission scenarios, in a factorial way, leading to a total of 32 combinations applied in the historical period and in two future periods, 2041-2070 (near future) and 2070-2099 (far future). We evaluated the RCM's performance under the historical period comparing the observed values measured in the rainfall gauge stations to the raw (uncorrected) models' simulations, as well as to the biascorrected simulations.

It is important to mention that, while mean precipitation is corrected by bias correction by definition, simulations can still be poor for specific precipitation indices like low or high precipitation (Addor and Seibert, 2014). Here, we analyzed several precipitation statistics beyond the daily precipitation, in order to evaluate the performance of bias correction in multiday rainfall events, including the low precipitation, defined as the minimum 30-day precipitation amount and the high precipitation, defined as the maximum 4-day precipitation amount. Besides, monthly precipitation, as well as seasonal amounts, were computed (DJF - December, January, February, MAM - March, April, May, JJA - June, July, August, and SON - September, October, November) and analyzed.

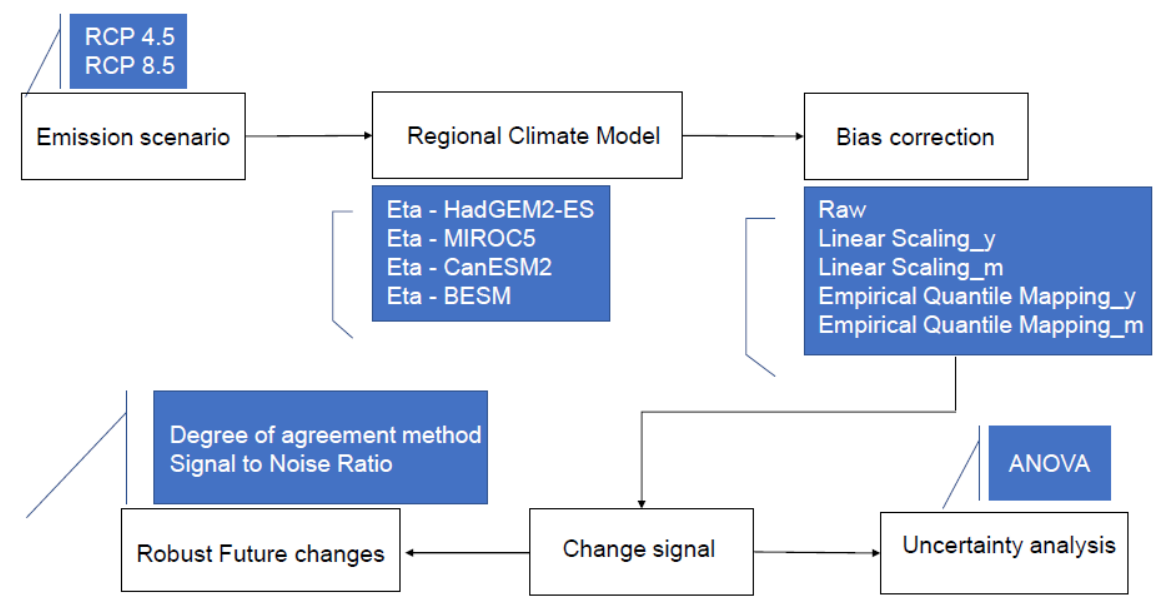

Figure 2 - Flowchart of the experimental design. The boxes represent the model chain elements. For each element, several methods were used which are listed under or above the boxes and described in the main text.

\section{Results}

In this section, we address the biases in the regional climate model outputs and the effect of bias correction methods on the simulated precipitation, the uncertainty contribution of each factor (climate models, bias correction and emission scenarios) in the total uncertainty and the projections of robust changes in precipitation for Brazil. 
4.1 Raw climate model simulations and bias correction

There is a spatial variability of the uncorrected climate models' biases magnitude across Brazil. The highest raw (uncorrected) simulation biases in millimiters are in the Amazon region, and North Brazil, as well as in one individual gauge station in Southern Brazil (Figure 3-a). Coincidentally, these regions are the most humid between the gauge stations analysed. In relative terms (\%), the highest biases are located in the Amazon and North region (Figure 3-b).

All models have similar performance in average. The daily simulations climate models' biases range from $0.03 \mathrm{~mm}$ to $4.64 \mathrm{~mm}$ per day, being in average around $1.33 \mathrm{~mm}$. For the daily and monthly amounts of precipitation, the HadGEM2-ES model is slightly better than the other models, but for a better understanding of the biases characteristics, we advise the reader to see the boxplots for all the precipitation statistics in Figure S1, in the Supplementary Materials.

The effect of the bias correction on the reduction of bias in simulated precipitation is presented in the Table 2. According to the calculated performance measure, all bias corrections methods improved the raw RCM simulations. However, the matching between observed and simulated precipitation after the bias correction did not differ significantly between the bias correction methods for the daily and monthly series. Nevertheless, the methods did differ for particularly precipitation statistics (low, high and seasonal), being the monthly correction factor version of the LS and EQM better than using a single yearly correction factor. Besides that, there is an obvious loss in the correction performance when we apply the correction factors estimated in the training period on an independent dataset (test).

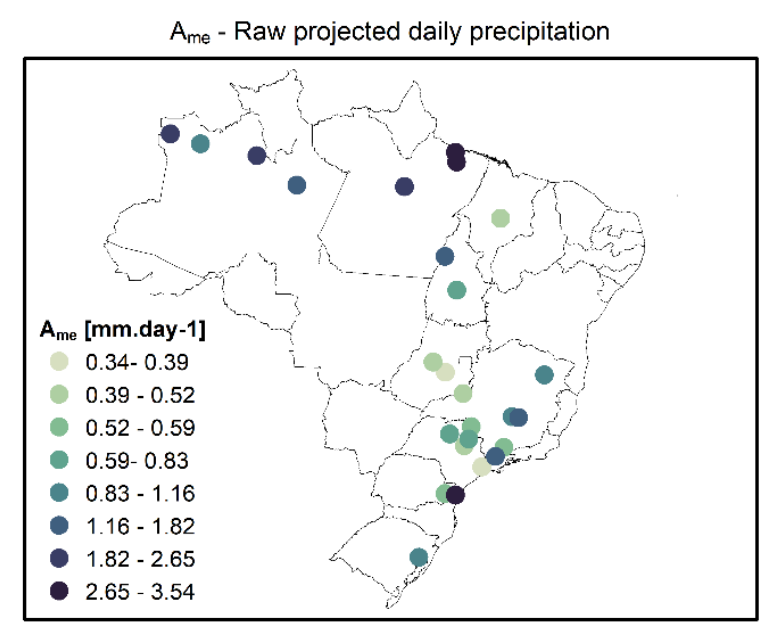

a

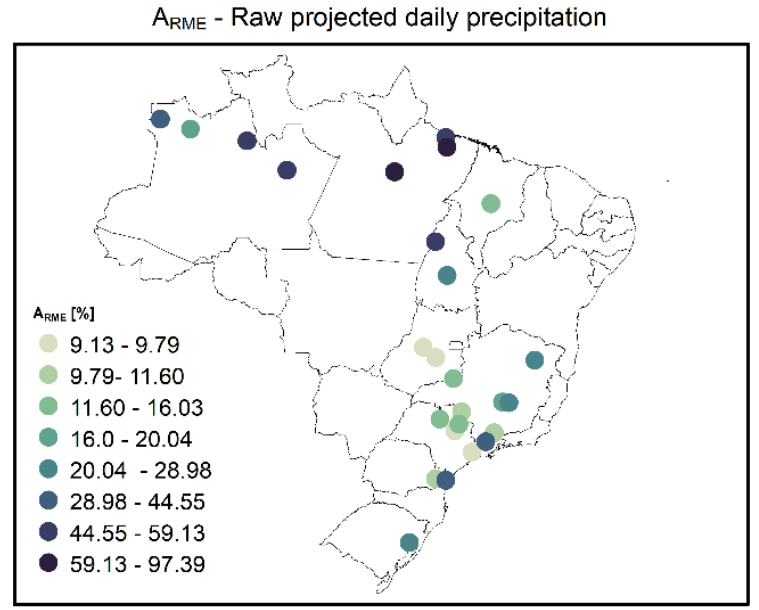

b

Figure 3. Raw simulations biases from the Eta Regional Climate Model over Brazil. The biases are the average of four RCM-GCMs. (a) Absolute value of the Mean Error $\left(A_{m e}\right)$; (b) Absolute value of the Relative Mean Error (Arme).

Table 2. Average of the Absolute value of the Mean Error ( $\left.A_{m e}\right)$ for the Training and Test period based on 26 precipitation gauge stations before (Raw) and after the bias correction through Linear Scaling (LS) (yearly and monthly factors) and Empirical Quantile Mapping (EQM) (yearly and monthly factors). 


\begin{tabular}{|c|c|c|c|c|c|}
\hline & Raw & LS_y & LS_m & EQM_y & EQM_m \\
\hline \multicolumn{6}{|c|}{ Training } \\
\hline Daily [mm.day $\left.{ }^{-1}\right]$ & 1.38 & 0.00 & 0.00 & 0.42 & 0.54 \\
\hline High $\left[\mathrm{mm} .4\right.$ day $\left.^{-1}\right]$ & 48.76 & 41.78 & 39.86 & 24.49 & 14.58 \\
\hline Low $\left[\mathrm{mm} .30 \mathrm{day}^{-1}\right]$ & 11.59 & 10.89 & 8.52 & 11.45 & 5.08 \\
\hline Monthly[mm.month $\left.{ }^{-1}\right]$ & 41.22 & 0.00 & 0.00 & 1.54 & 1.09 \\
\hline $\mathrm{DJF}\left[\mathrm{mm} \cdot\right.$ season $\left.^{-1}\right]$ & 152.58 & 107.27 & 3.74 & 93.05 & 6.91 \\
\hline MAM [mm.season $\left.{ }^{-1}\right]$ & 175.71 & 93.20 & 2.08 & 96.74 & 4.58 \\
\hline $\mathrm{JJA}\left[\mathrm{mm}\right.$ season $\left.^{-1}\right]$ & 132.56 & 103.09 & 2.01 & 91.60 & 3.84 \\
\hline SON $\left[\mathrm{mm}_{\text {. season }}{ }^{-1}\right]$ & 139.39 & 104.54 & 2.58 & 94.27 & 5.99 \\
\hline \multicolumn{6}{|c|}{ Test } \\
\hline Daily $\left[\mathrm{mm} \cdot \mathrm{day}^{-1}\right]$ & 1.36 & 0.55 & 0.60 & 0.63 & 0.87 \\
\hline High $\left[\mathrm{mm} .4 \mathrm{day}^{-1}\right]$ & 42.92 & 32.78 & 38.80 & 22.79 & 20.34 \\
\hline Low $\left[\mathrm{mm} .30 \mathrm{day}^{-1}\right]$ & 11.26 & 10.23 & 9.45 & 10.91 & 7.23 \\
\hline Monthly [mm.month $\left.{ }^{-1}\right]$ & 40.36 & 16.33 & 17.19 & 16.78 & 17.87 \\
\hline $\mathrm{DJF}\left[\mathrm{mm}\right.$ season $\left.^{-1}\right]$ & 156.18 & 124.37 & 68.72 & 113.20 & 72.51 \\
\hline MAM [mm.season $\left.{ }^{-1}\right]$ & 198.31 & 121.79 & 63.93 & 122.97 & 71.43 \\
\hline JJA $\left[\mathrm{mm}_{\mathrm{season}}{ }^{-1}\right]$ & 140.88 & 123.28 & 46.78 & 109.27 & 52.34 \\
\hline SON $\left[\mathrm{mm}^{\mathrm{season}}{ }^{-1}\right]$ & 149.74 & 128.28 & 56.00 & 118.59 & 60.66 \\
\hline
\end{tabular}

For the test period, we also present the comparison between observed and simulated longterm precipitation means (Figure 4-a) and observed and simulated Cumulative Distribution Function (Figure 4-b) for the Amazon region (for more rainfall gauge stations, see the Figure S2 in the Supplementary material, where we present, at least one precipitation gauge station at each of the hydrographical regions under study in Brazil). Figure 4 shows that the raw simulations follow quite well the hydrological seasonality, but lacks in accuracy to the true values (observed means), attesting to the need of bias correction to match the simulated to the observed values.

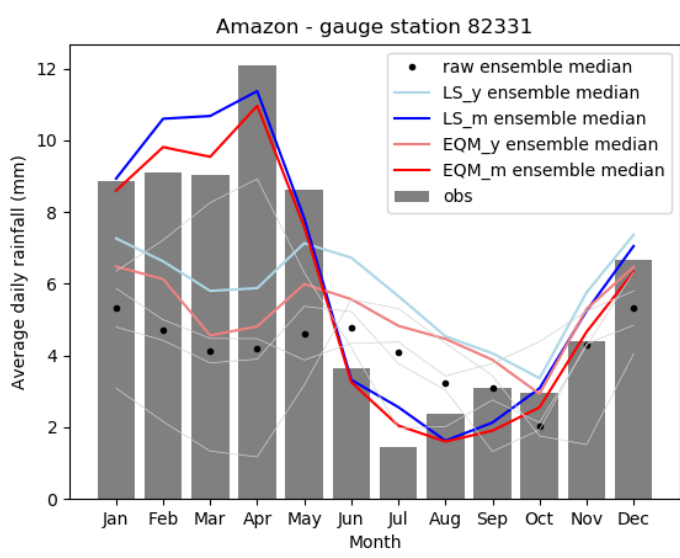

a

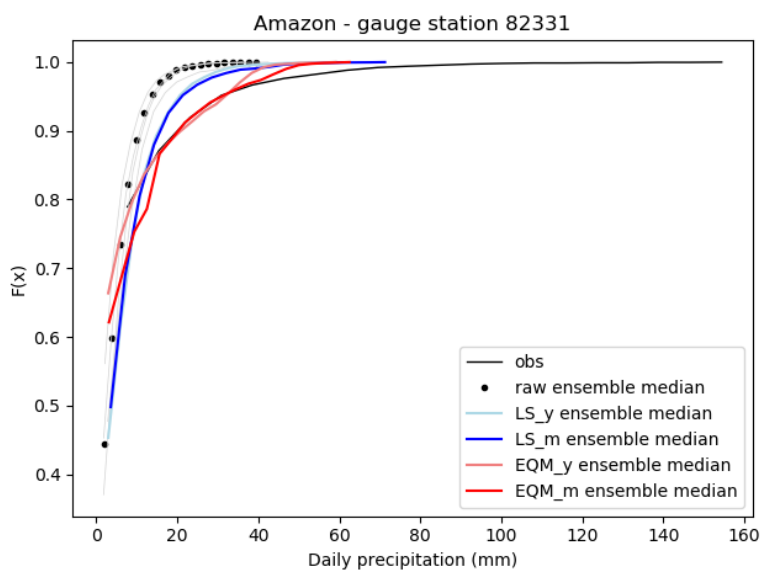

b

Figure 4. Comparison between average observed, raw ensemble median and bias-corrected by Linear Scaling (yearly and monthly factors) and Empirical Quantile Mapping (yearly and monthly factors), as well as 
individual raw model simulations in light-grey lines of the monthly precipitation (a) and observed, raw simulated and corrected by Cumulative Distribution Function (b) for the test period (1997 - 2005).

\subsection{Uncertainty analysis}

The Analysis of Variance (ANOVA) was performed to quantify the respective contribution of three uncertainty sources to the total uncertainty in projected precipitation, namely in the climate models, bias correction and emission scenario.

\subsubsection{Daily, high and low precipitation}

The main factors (Climate model $-\mathrm{C}$, Bias Correction $-\mathrm{B}$ and Emission scenario $-\mathrm{E}$ ) and the interactions between these factors $(\mathrm{C}: \mathrm{E}, \mathrm{C}: \mathrm{B}$ and $\mathrm{E}: \mathrm{B})$ significance to the total uncertainty are summarised in the Figure S3-a, Figure S3-b and Figure S3-c in the Supplementary Materials for the daily, high and low precipitation, respectively. The significance of the main effects and first-order interactions of the ANOVA model was evaluated by the F-test, at the significance level of 0.05. A p-value smaller or equal the significance level $(\alpha=0.05)$ indicated that the factor and/or interaction uncertainty contribution was significant for the projected precipitation and should be included in the final ANOVA model.

The contribution of each source of uncertainty found as relevant through the F-test is presented in Table 3. The major contribution to the total uncertainty in the daily, high and low precipitation statistics correspond to the bias correction, climate model and the interaction between climate model and bias correction, while there is a small contribution due to the emission scenario and interaction between climate model and emission scenario.

Table 3 - Average variance fraction of the significant main factors and first order interactions in the near and far future per precipitation statistic (daily, high and low precipitation). The highest values for uncertainty contributions are in bold.

\begin{tabular}{clccc}
\hline \multirow{2}{*}{ Future period } & \multicolumn{3}{c}{ Description } & \multicolumn{3}{c}{ Average variance fraction (\%) } \\
& & Daily & High & Low \\
\cline { 2 - 4 } Near & Climate model & $\mathbf{4 3 . 5 8}$ & 21.15 & 18.1 \\
& Bias correction & 40.66 & $\mathbf{5 2 . 6 4}$ & $\mathbf{3 4 . 2 3}$ \\
& Emission Scenario & 0.6 & & \\
& Climate model : Emission Scenario & 1.14 & & \\
& Climate model : Bias Correction & 12.92 & 23.3 & 31.34 \\
& Residual & 1.1 & 2.91 & 19.55 \\
\hline \multirow{5}{*}{ Far } & Climate model & 34.84 & 19.96 & 17.78 \\
& Bias correction & $\mathbf{3 8 . 9 3}$ & $\mathbf{4 7 . 8 7}$ & $\mathbf{2 9 . 6}$ \\
& Emission Scenario & 3.07 & 2.22 & 6.52 \\
& Climate model : Emission Scenario & 4.66 & & \\
& Climate model : Bias Correction & 14.62 & 24.59 & 26.43 \\
& Residual & 3.87 & 5.36 & 22.76 \\
\hline
\end{tabular}




\subsubsection{Seasonal precipitation}

According to the F-test (Figure S4), we assumed as significant for the seasonal ANOVA model the main factors climate model, bias correction and interaction between climate model and bias correction. The variance fractions of the main significant factors and interaction elements are presented in Table 4

In general, the bias correction is the main contributor to the total uncertainty of the seasonal precipitations for both near and far future, followed by the interaction between climate model and bias correction.

Table 4 - Average variance fraction $(\eta)$ of the significant main factors and first order interactions in the near (2041 - 2070) and far (2070 - 2099) future per season. The highest values for uncertainty contributions are in bold.

\begin{tabular}{llcccc}
\hline \multirow{2}{*}{ Future period } & \multirow{2}{*}{ Description } & \multicolumn{3}{c}{ Average variance fraction (\%) } \\
& & DJF & JJA & MAM & SON \\
\hline \multirow{4}{*}{ Near } & Climate model & 22.67 & 9.71 & 24.66 & 8.48 \\
& Bias correction & $\mathbf{4 1 . 1 4}$ & $\mathbf{4 6 . 2 7}$ & $\mathbf{4 5 . 6 1}$ & $\mathbf{4 7 . 0 8}$ \\
& Climate model : Bias Correction & 32.31 & 37.89 & 27.19 & 42.26 \\
& Residual & 3.88 & 6.14 & 2.54 & 2.18 \\
\hline \multirow{4}{*}{ Far } & Climate model & 18.07 & 8.95 & 21 & 7 \\
& Bias correction & $\mathbf{3 8 . 4}$ & 41.59 & $\mathbf{4 5 . 7}$ & $\mathbf{4 5 . 0 2}$ \\
& Climate model : Bias Correction & 34.39 & $\mathbf{4 2 . 2 7}$ & 26.24 & 41.05 \\
& Residual & 9.14 & 7.2 & 7.06 & 6.93
\end{tabular}

\subsection{Precipitation changes for the future}

In this section, we present the future projected changes in precipitation for Brazil. The robust ensemble median changes after post-processing are presented in maps showing both the absolute changes on precipitation in millimetres $(\mathrm{mm})$ as well as the relative change in percentage $(\%)$. The robust precipitation changes are composed by the mean of all bias correction methods and the median of all the regional climate models under analysis after evaluating the robustness by two methods, the degree of agreement method and the $S_{N R}$. In the maps, the size of the bubbles represents the relative change and the colours the absolute changes in millimetres.

\subsubsection{Daily, high and low precipitation}

The absolute magnitude of the changes for the future is especially higher in the wettest gauge stations under analysis (annual precipitation amounts higher than $1500 \mathrm{~mm}$ ). Still, in relative terms, the changes are homogeneous between the regions. The RCP 8.5 scenarios tend to project stronger drier conditions in general, as well as the far future period projections (Figure S5 - absolute changes and Figure S6 - relative changes). Outliers and high variability outside the 
upper and lower quartiles were represented by diamond marks and the boxplot whiskers, respectively.

The precipitation changes corrected by correction methods are correlated to the raw precipitation changes, which suggests that the change signal could be correct even if the magnitude of the changes are not. The Figure 10 shows that in general the changes projected by the raw simulations are stronger (both in terms of increase or decrease in precipitation) than that estimated after bias correction and the post-processing technique that evaluated the robustness of the changes. In other words, the models can simulate well the future changes, but they fail in terms of accurary.
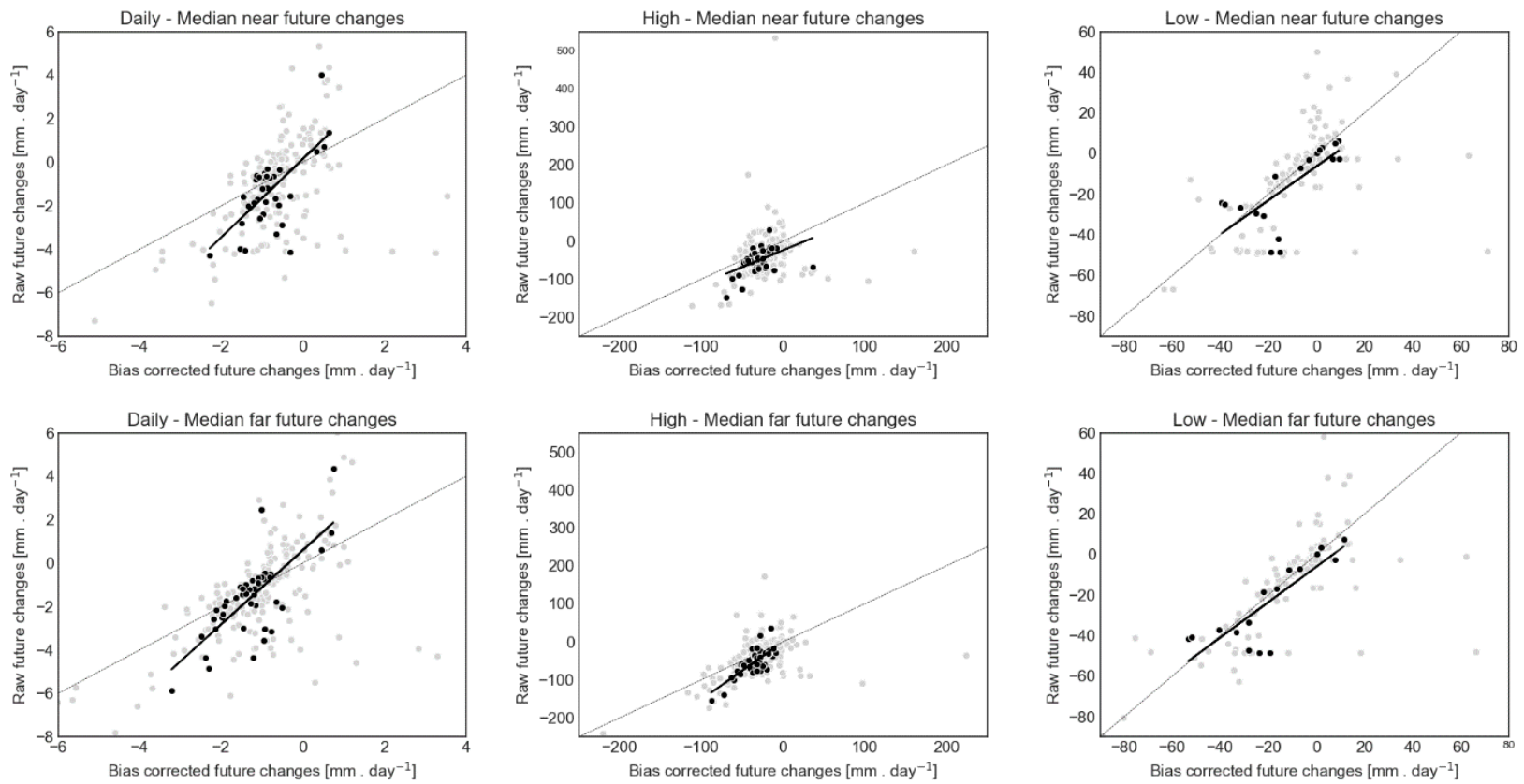

Figure 5. Scatter plot of the bias corrected future changes versus the raw future changes for the daily (first column), high (second column) and low (third column) precipitation indices for the near (first row) and far (second row) future. The grey dots represent the spread of model's simulation, while the black dots represent the robust ensemble median.

The precipitation change is presented in Figure 7-a, Figure 7-b and Figure 7-c for the daily, high and low precipitation respectively. Drier conditions are expected for the daily precipitation for North and Central region of Brazil and wetter conditions for Southern Brazil. For the high precipitation statistic, the projections indicate a decrease in precipitation. For most of the country, there are non-robust changes for the low precipitation statistic. However, a robust increase in the low precipitation is projected for North and South Brazil and decrease for the Amazon region.

The near future projections under the RCP 8.5 scenario are similar to the far future scenario under the RCP 4.5 scenario, which lead us to conclude that, earlier or sooner these changes are expected to happen anyways based on the amount of carbon dioxide expected to accumulate in the atmosphere. For the far future and RCP 8.5 scenario, the changes are especially stronger, representing the maximum quantity of carbon dioxide in the atmosphere under these scenarios. For this extreme scenario, an homogeneous decrease in precipitation is projected for the daily, high and low precipitations over the country. 
Change in daily precipitation

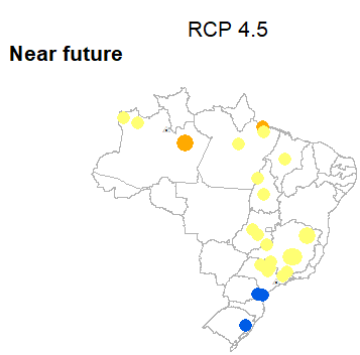

Far future

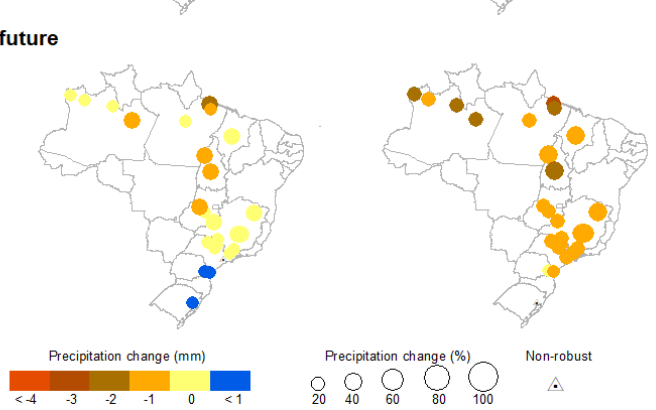

a
RCP 8.5

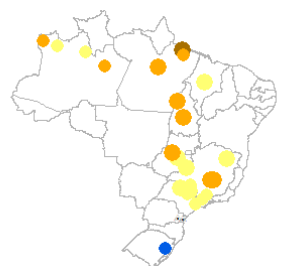

Change in high precipitation

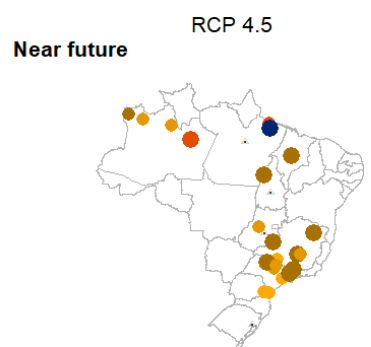

Far future

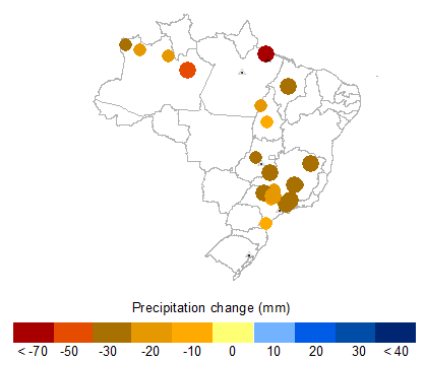

RCP 8.5
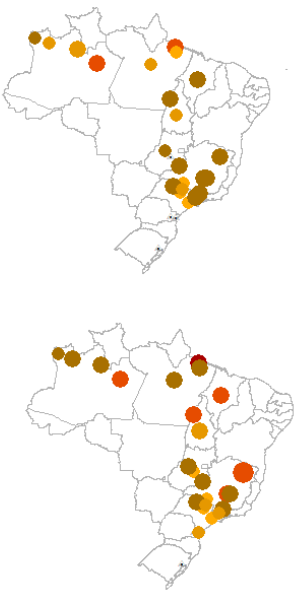

Precipitation change (\%) Non-robust

b

\section{Change in low precipitation}

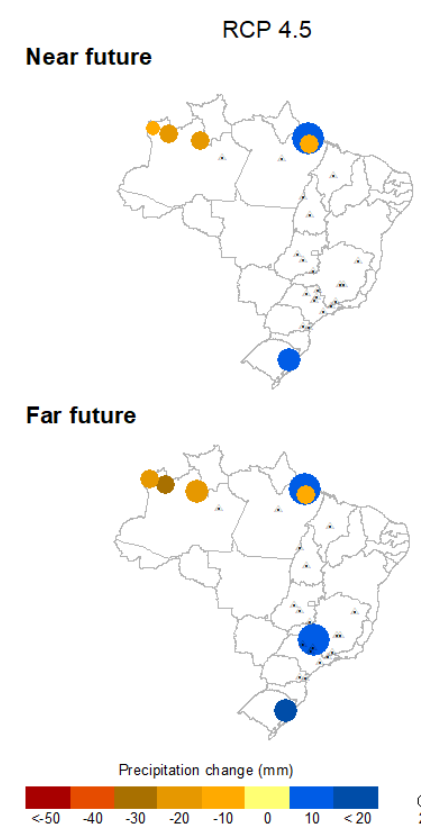

RCP 8.5

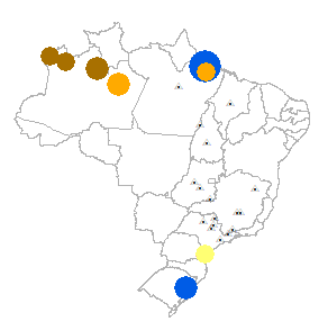

Far future

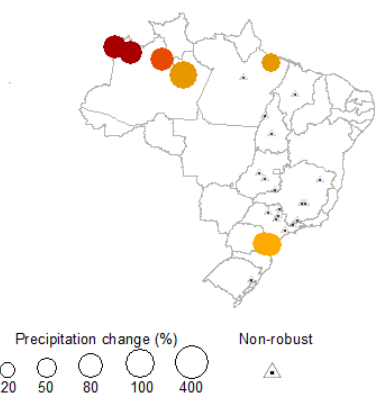

c

Figure 6. Ensemble median change ( $\mathrm{mm}$ ) in daily (a), high (b) and low (c) precipitation for the near and far future in reference to the baseline (1961 - 1990). The size of the bubbles represents the relative change while the colors represent the absolute change.

There is a positive correlation between the changes for the near and far future (Figure 7 a), as well as a positive correlation between the RCP4.5 and RCP8.5 scenarios (Figure $7-b$ ). The changes are slightly stronger for the far future, both when the precipitation increases or decreases. Overall, the RCP 8.5 resulted in more significative decreases. The signal of the change usually varies depending on the gauge station (increase or decrease). However, for the high precipitation, there is a declining trend for all the analysed gauge stations. Although the 
magnitude of the changes for the wettest gauge stations be stronger, we observe the same pattern in the correlation between the near and far future projections (Figure 11-a).
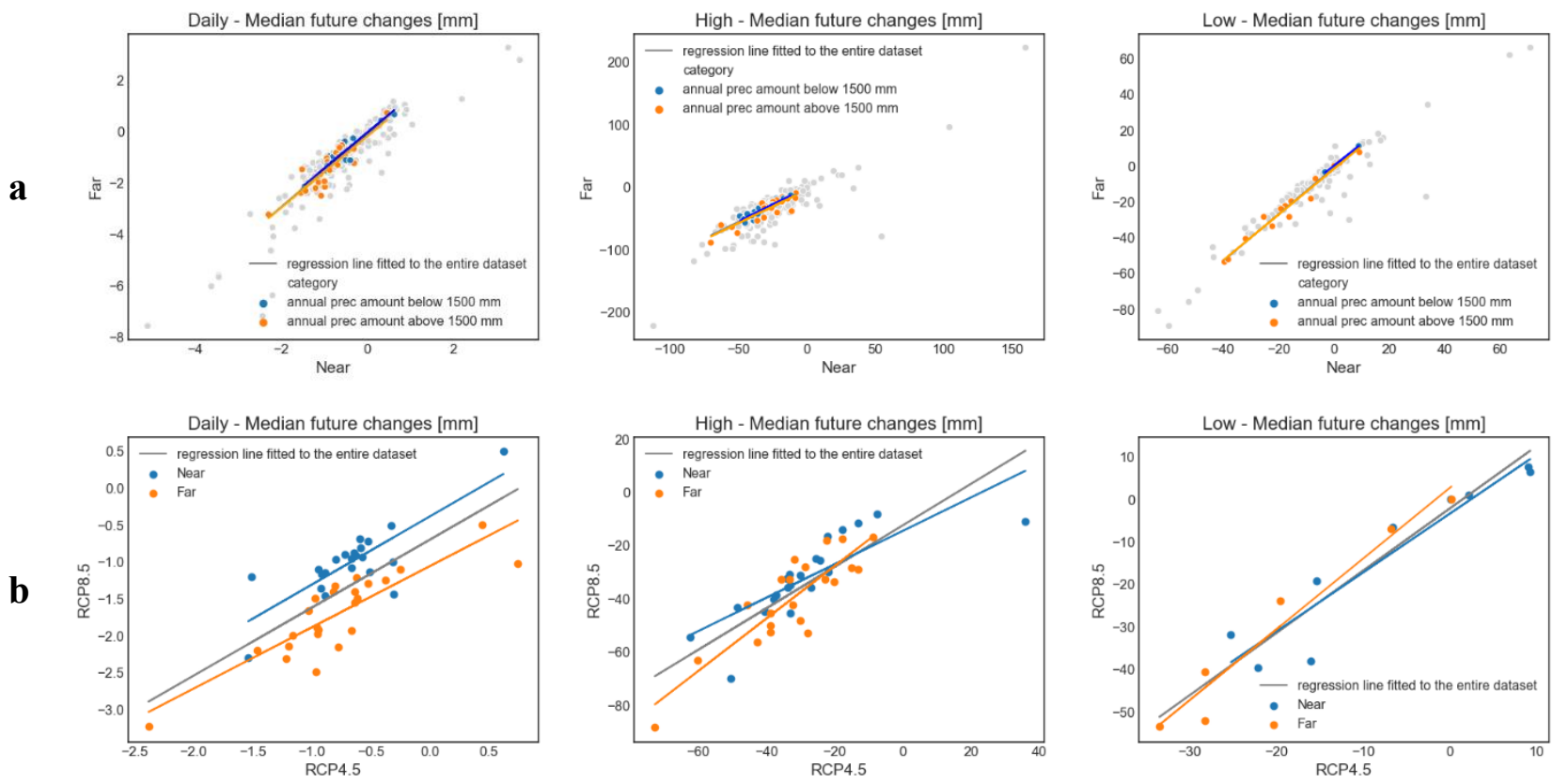

Figure 7. Correlation between near and far future (left column - a) and RCP 4.5 and RCP 8.5 scenarios (righ column - b) for the daily, high and low precipitation.

\subsubsection{Seasonal precipitation}

Stronger absolute changes are expected to the wettest regions in Brazil, and more accentuated in the far future (Figure S7), independently of the season. In contrast, the relative changes are mostly homogeneous over the country (Figure S8).

The climate models projected mainly decreases in the seasonal precipitations for North and Center region of Brazil and increase for Southern, excepting for the winter, where most of the regions are expected to have increases in the precipitation (Figure 8). 


\section{Change in seasonal precipitation}

Near future
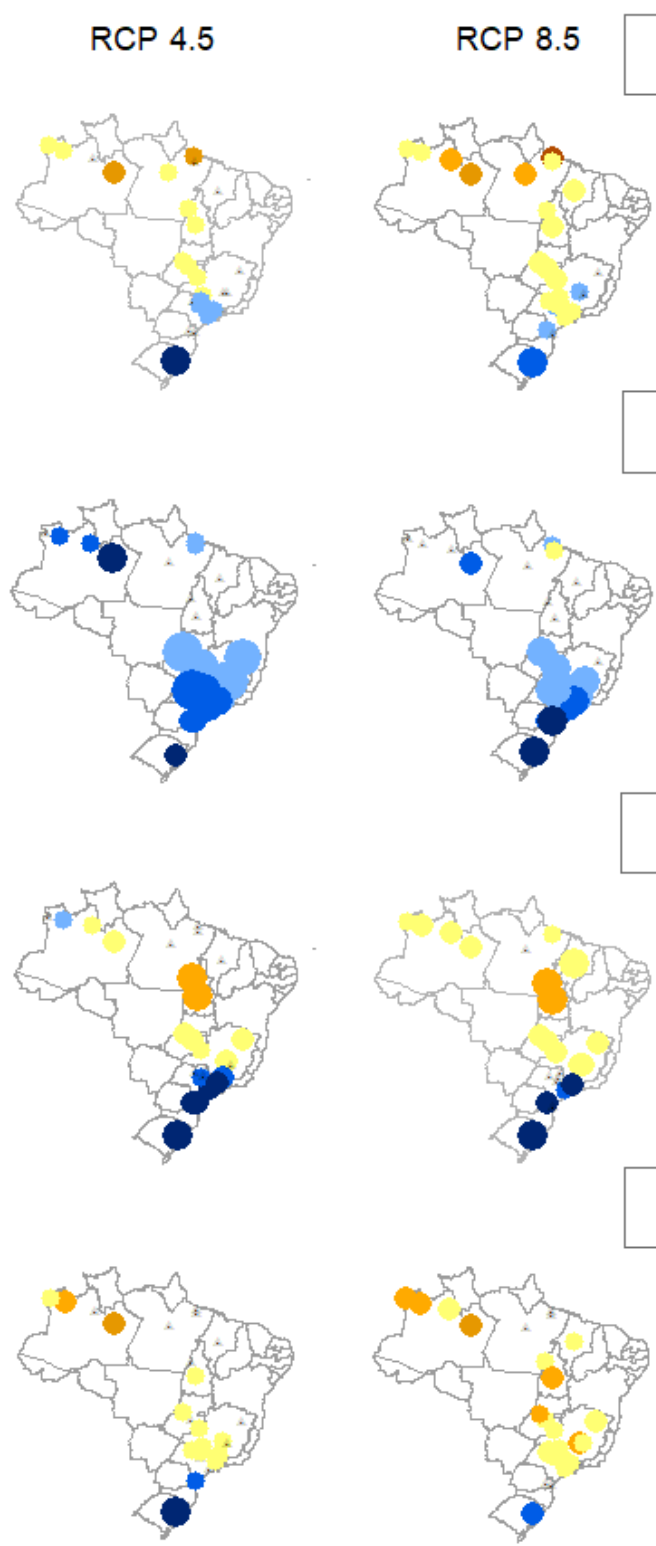

DJF

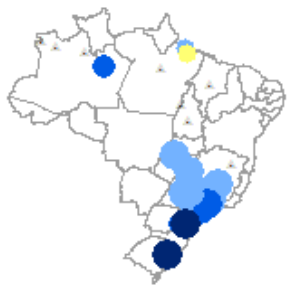

MAM

RCP 4.5

Far future
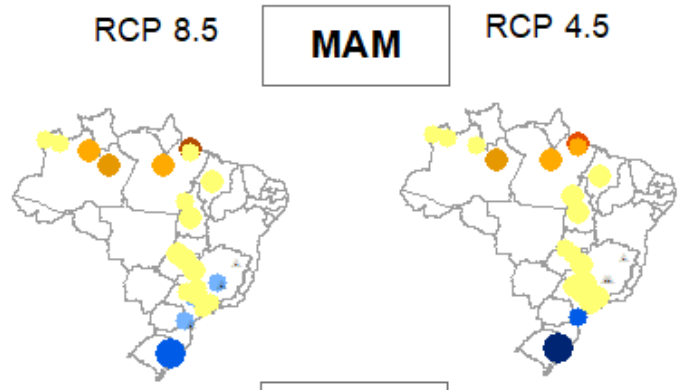

JJA
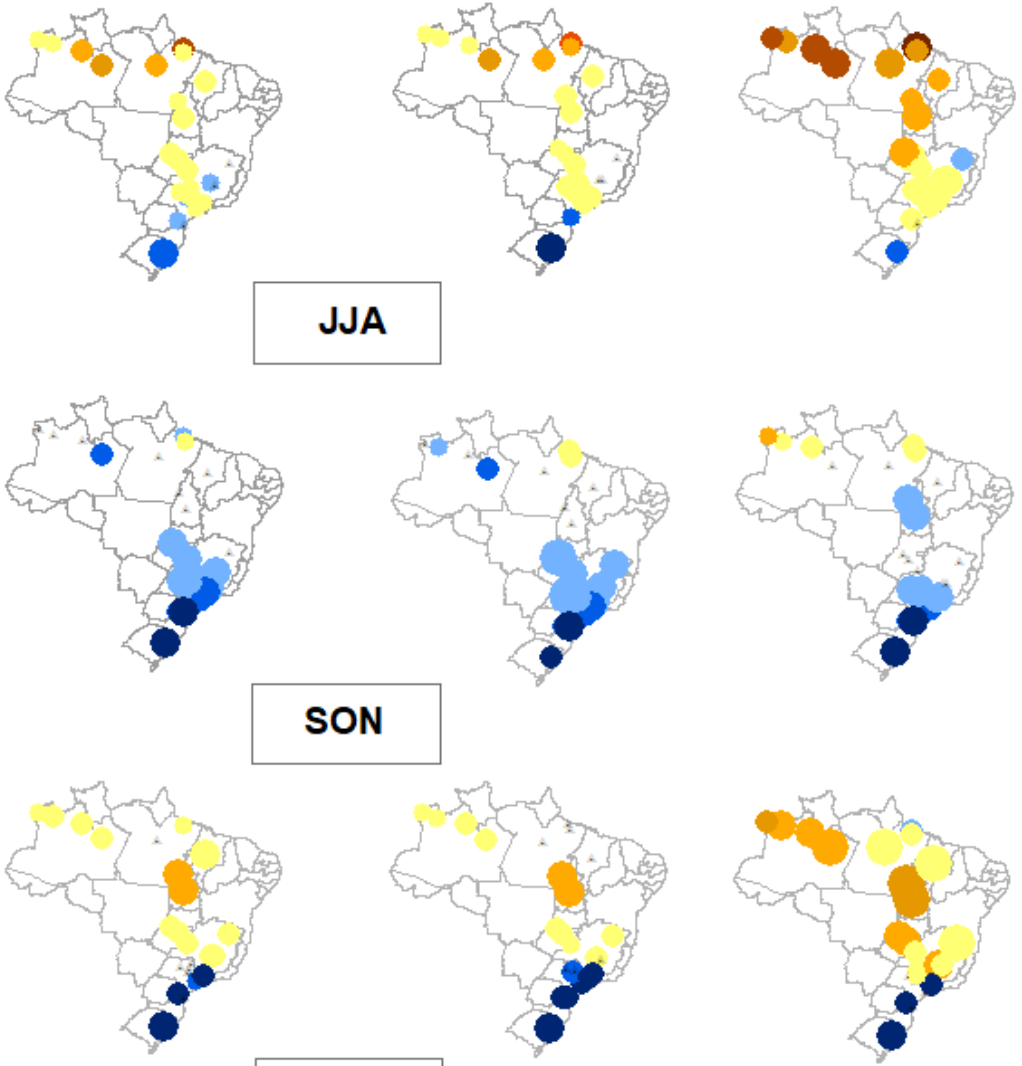

RCP 8.5
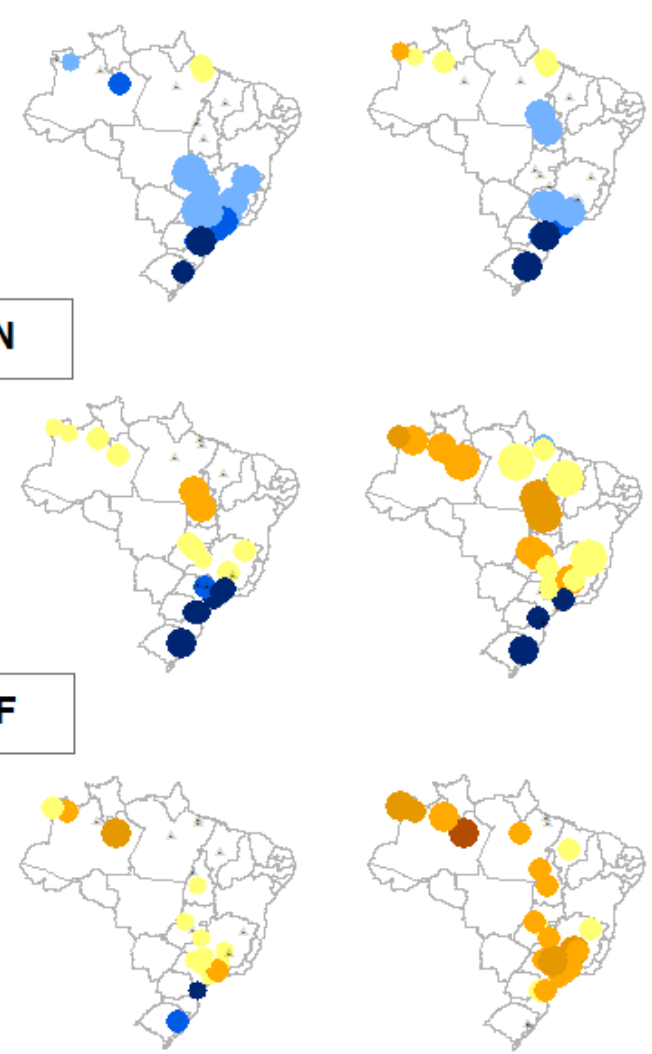

Precipitation change $(\mathrm{mm})$

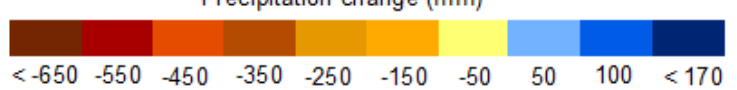

Precipitation change (\%) Non-robust

$\bigcirc 000$

$100 \quad 80 \quad 60 \quad 40 \quad 20$

Figure 8. Ensemble median change (mm.season ${ }^{-1}$ ) in seasonal precipitation for the near and far future in reference to the baseline (1961 - 1990).

Similar to the daily, high and low precipitation statistics, there is a positive correlation between the changes for the near and far future, as well as between the emission scenarios. Usually, the RCP 8.5 presents more significative changes of decreasing. The changes are slightly stronger for the far future, both when the precipitation increases or decreases, but especially for the decreasing projections. The signal of the change usually varies depending on the gauge 
station (increase or decrease), however, for the gauge stations with precipitation above $1500 \mathrm{~mm}$, the range of the changes is higher.

\section{Discussion}

5.1 How well the Eta regional climate model simulates precipitation over Brazil?

There were large biases from the regional climate models. Despite that, the comparison between the long-term monthly means of observed and raw simulated precipitation in the historical period pointed out good correspondence between the observed and simulated annual cycle, indicating correct representations of dynamical and/or physical processes which make statistical bias correction applicable (Haerter et al., 2011).

5.2 How the bias correction affects the reduction of models' biases?

After the bias correction, there was a bias reduction in the precipitation indices ranging from $-58 \%$ (monthly series) to $-16 \%$ (low precipitation series). There were no significant differences in performance between the methods applied (either if yearly or monthly correction factor or LS and EQM) for the daily and monthly series, however the monthly correction factor clearly performed better for the particularly seasonal and multiday precipitation, as well as for the Amazon region and North Brazil.

After the application of the bias correction, it was observed a good adjustment of the simulations to the observed values in the average precipitation and in the cumulative distributions for the test period $(1997-2005)$. These results emphasise the importance of the implementation of the bias correction before applying the simulations in impacting studies.

5.3 What is the contribution of climate models, bias correction and emission scenarios to the total uncertainty of projected precipitation?

The variance fraction shows that in general the major contribution to the uncertainty in the projected precipitation corresponds to the bias correction, followed by the climate model and the interaction between climate model and bias correction, and finally, in a very small proportion, the scenario and interaction between climate model and scenario.

Despite the similar results between the bias correction performances in the mean error reduction, the bias correction method was one of the major contributors to the uncertainty cascade in precipitation projections. Iizumi et al. (2017) estimated the importance of the bias correction methods and reference meteorological forcing data sets to uncertainty in projected temperature and precipitation extremes and concluded that although the contribution of the bias correction is minor than the GCMs or RCPs they yet are important in the climate change studies of extremes, however not important in the mean climate. In parallel with our work, we can point that the importance of the uncertainties sources highly depend on the variable under analysis. 
Extreme low and high precipitation show higher uncertainty from the bias correction method than the daily precipitation.

The residual variance fraction (ranging between 1 to $20 \%$ ) may be interpreted as the aleatory uncertainty deriving of the random behavior of the climate system. Nevertheless, the boundaries between aleatory and epistemic (human limited knowledge) are difficult to establish. Part of the attributed aleatory uncertainty may be caused by our insufficient knowledge of initial conditions of the climate system, therefore a climate model limitation, and hence, in principle, subject to reduction (Maraun and Widmann, 2018, Haukin and Sutton, 2009).

The residual would be more understandable/interpretable if we added to the uncertainty analysis cascade the outputs of different members of the models, the members being simulations with different initial conditions, and the uncertainty due to this factor termed as internal climate variability. Internal variability is defined as the natural variability of the climate system that occur in the absence of external forcing (e.g. emission scenarios), including processes intrinsic to the atmosphere, the ocean and the coupled ocean-atmosphere system (Deser et al., 2012).

Deser el al. (2012) estimated that the internal variability represents at least half of the inter-model spread in projected climate trends during 2005-2060 at the decadal - scale in the CMIP3 multi-model ensemble, concluding that the climate change assessment should consider this source of uncertainty by running enough ensemble members. However, in practice, the competition between model resolution and ensemble size is an issue given the limited computational resources. Hawkins and Sutton (2011) argued that in general, the importance of internal variability increases at smaller spatial scales and shorter time scales (a decade or two) while for time horizons of many decades or longer, the dominant sources of uncertainty at regional or larger spatial scales are model and scenario uncertainty.

The uncertainty contribution is independent of the future under analysis. Finally, these results indicate the importance of the bias correction in climate change assessments and the need of improvement of the climate models in the future, as well as approaches that reduce the uncertainty in this factor in the impact analysis framework and the importance of addressing uncertainties in the climate change communication.

5.4 What are the precipitation changes projected over Brazil?

There is high dispersion among the individual model projections for the precipitation change, including incongruence in the signal of the change, in which some models project a negative change while other a positive. This indicates that the choice of the model directly affects the future projection, potentially affecting all the forward climate change cascade of analysis, including the results of impact models. Given that, we highly suggest the use of multimodel ensembles as a way to reduce the uncertainties in future projections.

The ensemble spread summarises the information about the uncertainties related to the model errors. In this study, we used the ensemble median as a way of contemplating the uncertainty and we performed two robustness tests to evaluate the likelihood and significance of the change projections. Most of the changes were considered significant when compared to the natural variability, except for the low precipitation. 
When the climate change signal of the raw simulations was compared to the biascorrected simulations, we observed an agreement in the signal of the change (increase or decrease). However, the raw simulations projects stronger changes and since they failed in accuracy in historical period, we would say that they also fail in future magnitude projections.

In general terms, it is projected a reduction in daily precipitation indices in the Amazon region, North and Center region, and an increase in Southern Brazil. Only in the winter season, it is projected a homogeneous increase in precipitation indices over Brazil. For most of the country, there are non-robust changes for the low precipitation statistics, except for increase in two individual gauge stations, one in North and one in South Brazil, and decrease in the Amazon region. The major decreases were observed under the RCP 8.5 scenario and far future. The results corroborate to the findings of other studies using different GCM-RCMs projections over Brazil, drier conditions are expected to occur in Brazil in the future.

\section{Conclusions}

The bias correction of raw simulations from regional climate models was demonstrated to be essential in climate change assessments, reducing significantly the models' biases. However, the raw simulations of regional climate models seem to project adequately the climate change signal despite failing in accuracy. In terms of uncertainties, the bias correction methods and climate models are the factors that more aggregate uncertainty in the projected precipitations.

The future projections of precipitation indicated overall a precipitation decrease for most of Brazil but an increase in Southern Brazil, confiring the results from past studies using different GCM-RCMs in the country/South America. Also, there is a homogeneous increase trend of precipitation in the winter.

\section{Acknowledgment}

The authors would like to thank the research funding agencies CAPES-Brazil and Swiss Government Excellence Scholarship for the scholarships granted to the first author at different periods of time during this research. We also thank the National Institute of Space Research (INPE) for providing the regional climate model data, and the National Institute of Meteorology (INMET) for providing the observed precipitation data.

\section{References}

Addor, N., Seibert, J., 2014. Bias correction for hydrological impact studies-beyond the daily perspective. Hydrological Processes, 28(17), 4823-4828, https://doi.org/10.1002/hyp.10238

Addor, N., Rössler, O., Köplin, N., Huss, M., Weingartner, R., Seibert, J., 2014. Robust changes and sources of uncertainty in the projected hydrological regimes of Swiss catchments. Water Resources Research, v. 50, n. 10, p. 7541-7562, https://doi.org/10.1002/2014WR015549

Amengual, A., Homar, V., Romero, R., Alonso, S., Ramis, C., 2012. A statistical adjustment of regional climate model outputs to local scales: application to Platja de Palma, Spain. Journal of Climate, v. 25, n. 3, p. 939-957, https://doi.org/10.1175/JCLI-D-10-05024.1 
Amorim, P.B.D. and Chaffe, P.L.B., 2019a. Integrating climate models into hydrological modelling: What's going on in Brazil? Revista Brasileira de Recursos Hídricos, 24, https://doi.org/10.1590/2318-0331.241920180176

Amorim, P.B. and Chaffe, P.B., 2019b. Towards a comprehensive characterization of evidence in synthesis assessments: the climate change impacts on the Brazilian water resources. Climatic Change, 155(1), 37-57, https://doi.org/10.1007/s10584-019-02430-9

Arnell, N., 2011. Uncertainty in the relationship between climate forcing and hydrological response in UK catchments. Hydrology and Earth System Sciences, v. 15, n. 3, p. 897-912, https://doi.org/10.5194/hess-15-897-2011

Ávila, A., Justino, F., Wilson, A., Bromwich, D. and Amorim, M., 2016. Recent precipitation trends, flash floods and landslides in southern Brazil. Environmental Research Letters, 11(11), 114029, https://doi.org/10.1088/1748-9326/11/11/114029

Bosshard, T., Carambia, M., Goergen, K., Kotlarski, S., Krahe, P., Zappa, M., Schär, C., 2013. Quantifying uncertainty sources in an ensemble of hydrological climate-impact projections. Water Resources Research, v. 49, n. 3, p. 1523-1536, https://doi.org/10.1029/2011WR011533

Carvalho, A.A.D., Montenegro, A.A.D.A., Silva, H.P.D., Lopes, I., de Morais, J.E. and da Silva, T.G, 2020. Tendências da precipitação pluvial e da temperatura no Nordeste brasileiro. Revista Brasileira de Engenharia Agrícola e Ambiental, 24(1), 15-23, https://doi.org/10.1590/18071929/agriambi.v24n1p15-23

Chagas, V.B.P., Chaffe, P.L.B., Addor, N., Fan, F.M., Fleischmann, A.S., Paiva, R.C.D., Siqueira, V.A., 2020. CAMELS-BR: Hydrometeorological time series and landscape attributes for 897 catchments in Brazil, Earth Syst. Sci. Data Discuss., https://doi.org/10.5194/essd-202067, in review, 2020.

Chylek, P.; Li, J.; Dubey, M.K.; Wang, M.; Lesins, G., 2011. Observed and model simulated 20th century Arctic temperature variability: Canadian Earth System Model CanESM2. Atmospheric Chemistry and Physics Discussions, v. 11, n. 8, p. 22893-22907, https://doi.org/10.5194/acpd-1122893-2011

Chou, S.C., Lyra, A., Mourão, C., Dereczynski, C., Pilotto, I., Gomes, J., Bustamante, J., Tavares, P., Silva, A., Rodrigues, D., Campos, D., Chagas, D., Sueiro, G.; Siqueira, G.; Nobre, P., Marengo, J., 2014. Evaluation of the Eta simulations nested in three global climate models. American Journal of Climate Change, v. 3, n. 5, p. 438-454, https://doi.org/10.4236/ajcc.2014.35039 
Collins, W.J., Bellouin, N., Doutriaux-Boucher, M., Gedney, N., Halloran, P., Hinton, T., Hughes, J., Jones, C. D., Joshi, M., Liddicoat, S., Martin, G., 2011. Development and evaluation of an Earth-System model-HadGEM2. Geosci. Model Dev. Discuss, 4(2), 997-1062, https://doi.org/10.5194/gmdd-4-997-2011

Costa, R.L., de Mello Baptista, G.M., Gomes, H.B., dos Santos Silva, F.D., da Rocha Júnior, R.L., de Araújo Salvador, M. and Herdies, D.L, 2020. Analysis of climate extremes indices over northeast Brazil from 1961 to 2014. Weather and Climate Extremes, 100254, https://doi.org/10.1016/j.wace.2020.100254

Deser, C., Phillips, A., Bourdette, V., Teng, H., 2012. Uncertainty in climate change projections: the role of internal variability. Climate dynamics, v. 38, n. 3-4, p. 527-546, https://doi.org/10.1007/s00382-010-0977-x

Ehret, U.; Zehe, E.; Wulfmeyer, V.; Warrach-Sagi, K.; Liebert, J., 2012. HESS Opinions" Should we apply bias correction to global and regional climate model data?". Hydrology and Earth System Sciences, v. 16, n. 9, p. 3391-404, https://doi.org/10.5194/hessd-9-5355-2012

Gosain, A.K.; Rao, S.; Basuray, D., 2006. Climate change impact assessment on hydrology of Indian river basins. Current Science, v. 90, n. 3, p. 346-353.

Haerter, J., Hagemann, S., Moseley, C., Piani, C., 2011. Climate model bias correction and the role of timescales. Hydrology and Earth System Sciences, v. 15, p. 1065-1073, https://doi.org/10.5194/hessd-7-7863-2010

Hakala, K., Addor, N., Teutschbein, C., Vis, M., Dakhlaoui, H. and Seibert, J., 2019. Hydrological Modeling of Climate Change Impacts, Encycl. Water Sci. Technol. Soc., 1-20, https://doi.org/10.1002/9781119300762.wsts0062, 2019.

Hattermann, F.F.; Vetter, T.; Breuer, L.; Su, B.; Daggupati, P.; Donnelly, C,; Fekete, B.; Flörke, F.; Gosling, S.N.; Hoffmann, P.; Liersch, S.; Masaki Y.; Motovilov, Y.; Müller, C.; Samaniego, L.; Stacke, T.; Wada, Y.; Yang, T.; Krysnaova, V., 2018. Sources of uncertainty in hydrological climate impact assessment: a cross-scale study. Environmental Research Letters, v. 13, n. 1, p. 015006, https://doi.org/10.1088/1748-9326/aa9938

Hawkins, E., Sutton, R., 2011. The potential to narrow uncertainty in projections of regional precipitation change. Climate Dynamics, 37(1-2), 407-418, https://doi.org/10.1007/s00382-0100810-6

Iizumi, T., Takikawa, H., Hirabayashi, Y., Hanasaki, N., Nishimori, M., 2017. Contributions of different bias-correction methods and reference meteorological forcing data sets to uncertainty in 
projected temperature and precipitation extremes. Journal of Geophysical Research: Atmospheres, v. 122, n. 15, p. 7800-7819, https://doi.org/10.1002/2017JD026613

Jung, T., 2005. Systematic errors of the atmospheric circulation in the ECMWF forecasting system, Q. J. Roy. Meteorol. Soc., 131,1045-1073, https://doi.org/10.1256/qj.04.93.

Kay, A.L., Davies, H.N.; Bell, V.A., Jones, R. G., 2009. Comparison of uncertainty sources for climate change impacts: flood frequency in England. Climatic Change, v. 92, p. 41-63, https://doi.org/10.1007/s10584-008-9471-4

Kundzewicz, Z.W.; Krysanova, V.; Benestad, R.E.; Hov, Ø.; Piniewski, M.; Otto, I.M., 2018. Uncertainty in climate change impacts on water resources. Environmental Science \& Policy, v. 79, p. 1-8. https://doi.org/10.1016/j.envsci.2017.10.008.

Lenderink, G.; Buishand, A.; Deursen, W., 2007. Estimates of future discharges of the river Rhine using two scenario methodologies: direct versus delta approach. Hydrology and Earth System Sciences, v. 11, n. 3, p. 1145-1159, https://doi.org/10.5194/hess-11-1145-2007

Magrin, G.O.; Marengo, J.A.; Boulanger, J.-P.; Buckeridge, M.S.; Castellanos, E.; Poveda, G.; Scarano, F.R.; Vicuña, S, 2014. 2014: Central and South America. In: Climate Change 2014: Impacts, Adaptation, and Vulnerability. Part B: Regional Aspects. Contribution of Working Group II to the Fifth Assessment Report of the Intergovernmental Panel on Climate Change [Barros, V.R., C.B. Field, D.J. Dokken, M.D. Mastrandrea, K.J. Mach, T.E. Bilir, M. Chatterjee, K.L. Ebi, Y.O. Estrada, R.C. Genova, B. Girma, E.S. Kissel, A.N. Levy, S. MacCracken, P.R. Mastrandrea, and L.L. White (eds.)]. Cambridge University Press, Cambridge, United Kingdom and New York, NY, USA, pp. 1499-1566.

Maraun, D., Widmann, M., 2018. Statistical downscaling and bias correction for climate research. Cambridge: Cambridge University Press, https://doi.org/10.1017/9781107588783.010

Marengo, J., 2004. Interdecadal variability and trends of rainfall across the Amazon basin. Theor Appl Climatol 78, 79-96, https://doi.org/10.1007/s00704-004-0045-8

Mastrandrea, M.D., Field, C.B., Stocker, T.F., Edenhofer, O., Ebi, K.L., Frame, D.J., Held, H., Kriegler, E., Mach, K.J., Matschoss, P.R., Plattner, G.-K., Yohe, G.W., Zwiers, F.W., 2010. Guidance Note for Lead Authors of the IPCC Fifth Assessment Report on Consistent Treatment of Uncertainties. Intergovernmental Panel on Climate Change (IPCC).

Meresa, H.K., Romanowicz, R.J., 2017. The critical role of uncertainty in projections of hydrological extremes. Hydrology and Earth System Sciences, v. 21, n. 8, p. 4245-4258, https://doi.org/10.5194/hess-21-4245-2017 
Mesinger, F., Chou, S.C., Gomes, J. L., Jovic, D., Bastos, P., Bustamante, J.F., Lazic, L., Lyra, A. A., Morelli, S., Ristic, I., Veljovic, K., 2012. An upgraded version of the Eta model. Meteorology and Atmospheric Physics, v. 116, n. 3-4, p. 63-79, https://doi.org/10.1007/s00703-012-0182-z

Moss, R.H.; Edmonds, J.A., Hibbard, K.A., Manning, M.R., Rose, S.K., Van Vuuren, D.P.; Carter, T.R.; Emori, S.; Kainuma, M.; Kram, T.; Meehl, G. A., 2010. The next generation of scenarios for climate change research and assessment. Nature, v. 463, n. 7282, p. 747-756, https://doi.org/10.1038/nature08823

Muerth, M.; Gauvin St-Denis, B.; Ricard, S.; Velázquez, J. A.; Schmid, J.; Minville, M.; Caya, D.; Chaumont, D.; Ludwig, R.; Turcotte, R., 2013. On the need for bias correction in regional climate scenarios to assess climate change impacts on river runoff. Hydrology and Earth System Sciences Discussions, p. 10205-10243, https://doi.org/10.5194/hess-17-1189-2013

Nobre, P.; Siqueira, L.S.P.; De Almeida, R.A.F.; Malagutti, M.; Giarolla, E.; Castelão, G.P.; Bottino, M.J.; Kubota, P.; Figueroa, S.N.; Costa, M.C.; Baptista J.R., M.; Irber J.R., L.; Marcondes, G.G., 2013. Climate simulation and change in the Brazilian Climate Model. Journal of Climate, 26, 6716-6732. https://doi.org/10.1175/JCLI-D-12-00580.1

Prudhomme, C.; Davies, H., 2009. Assessing uncertainties in climate change impact analyses on the river flow regimes in the UK. Part 1: Baseline climate. Climatic Change, v. 93, p. 177-195, https://doi.org/10.1007/s10584-008-9464-3

Rao, V.B.; Hada, K., 1990. Characteristics of rainfall over Brazil: Annual variations and connections with the Southern Oscillation. Theoretical and Applied Climatology, 42(2), 81-91, https://doi.org/10.1007/BF00868215

Sá, E.A.S., Moura, C.N.D., Padilha, V.L. and Campos, C.G.C., 2018. Trends in daily precipitation in highlands region of Santa Catarina, southern Brazil. Revista Ambiente \& Água, 13(1), https://doi.org/10.4136/ambi-agua.2149

Shrestha, B., Cochrane, T.A., Caruso, B.S., Arias, M.E. and Piman, T., 2016. Uncertainty in flow and sediment projections due to future climate scenarios for the $3 \mathrm{~S}$ Rivers in the Mekong Basin. Journal of Hydrology, 540, pp.1088-1104, https://doi.org/10.1016/j.jhydrol.2016.07.019

Solomon, S.D., Qin, D., Manning, M., Chen, Z., Marquis, M., Avery, K.B., Tignor, M., Miller, H.L. (eds.), 2007. Contribution of Working Group I to the Fourth Assessment Report of the Intergovernmental Panel on Climate Change, 2007, Cambridge University Press, Cambridge, United Kingdom and New York, NY, USA. 
Steele-Dunne, S., Lynch, P., Mcgrath, R., Semmler, T., Wang, S., Hanafin, J., Nolan, P., 2008. The impacts of climate change on hydrology in Ireland. Journal of hydrology, v. 356, n. 1-2, p. 28-45, https://doi.org/10.1016/j.jhydrol.2008.03.025

Teutschbein, C.; Seibert, J., 2013. Is bias correction of regional climate model (RCM) simulations possible for non-stationary conditions? Hydrology and Earth System Sciences, v. 17, n. 12, p. 5061-5077, https://doi.org/10.5194/hess-17-5061-2013

Thodsen, H., 2007. The influence of climate change on stream flow in Danish rivers. Journal of Hydrology, v. 333, p. 226-238, https://doi.org/10.1016/j.jhydrol.2006.08.012

Trenberth K.E., 2011. Changes in precipitation with climate change. Climate Research. 47(1-2), 123-38, https://doi.org/10.3354/cr00953

Von Storch, H., Zwiers, F.W., 2009. Statistical Analysis in Climate Research. Cambridge University Press: Australia.

Watanabe, M., Suzuki, T., O’ishi, R., Komuro, Y., Watanabe, S., Emori, S., Takemura, T., Chikira, M., Ogura, T., Sekiguchi, M. and Takata, K., 2010. Improved climate simulation by MIROC5: Mean states, variability, and climate sensitivity. Journal of Climate, 23(23), pp.63126335, https://doi.org/10.1175/2010JCLI3679.1

Wilby, R.L., Harris, I., 2006. A framework for assessing uncertainties in climate change impacts: Low-flow scenarios for the river Thames, UK. Water Resources Research, v. 42, n. 2 , https://doi.org/10.1029/2005WR004065

Woldemeskel, F.M., Sharma, A., Sivakumar, B., Mehrotra, R., 2012. An error estimation method for precipitation and temperature projections for future climates. Journal of Geophysical Research: Atmospheres, 117(D22), https://doi.org/10.1029/2012JD018062

Woldemeskel, F.; Sharma, A.; Sivakumar, B.; Mehrotra, R., 2014. A framework to quantify GCM uncertainties for use in impact assessment studies. Journal of Hydrology, v. 519, p. 1453-1465, 2014, https://doi.org/10.1016/j.jhydrol.2014.09.025

WORLD METEOROLOGICAL ORGANISATION., 2017. WMO Guidelines on the calculation of climate normals.

Zandonadi, L., Acquaotta, F., Fratianni, S. and Zavattini, J.A., 2016. Changes in precipitation extremes in Brazil (Paraná River basin). Theoretical and Applied Climatology, 123(3-4), pp.741756, https://doi.org/10.1007/s00704-015-1391-4 
Zilli, M.T., Carvalho, L.M., Liebmann, B. and Silva Dias, M.A., 2017. A comprehensive analysis of trends in extreme precipitation over southeastern coast of Brazil. International Journal of Climatology, 37(5), pp.2269-2279, https://doi.org/10.1002/joc.4840

Zorndt, A.C.; Schlurmann, T., 2019. Sources of uncertainty in estuarine climate impact modeling, Journal of Applied Water Engineering and Research, v. 7, n. 1, p. 3747, https://doi.org/10.1080/23249676.2017.1355756 